\title{
Visceral fat index: a novel predictor for coronary collateral circulation
}

Departments of Internal Medicine, University of Health Sciences Antalya Training and Research Hospital, Antalya, Turkey ${ }^{2}$ Departments of Cardiology, University of Health Sciences Antalya Training and Research Hospital, Antalya, Turkey

${ }^{3}$ Department of Biostatistics Akdeniz University, Antalya, Turkey

Correspondence to:

Yasin Sahinturk

Department of Internal Medicine,

University of Health Sciences

Antalya Training and Research

Hospital Kazim Karabekir Caddesi

07100 - Antalya, Turkey

drsahinturk@yahoo.com

Received on June/3/2019

Accepted on Sept/30/2019

DOI: 10.20945/2359-3997000000218

\author{
Yasin Sahinturk ${ }^{1}$ \\ https://orcid.org/0000-0003-4907-0766 \\ Selcuk Kucukseymen ${ }^{2}$ \\ https://orcid.org/0000-0002-9757-3088 \\ Rauf $\mathrm{Avci}^{2}$ \\ https://orcid.org/0000-0002-8453-205X \\ Ayse Akarsu ${ }^{1}$ \\ https://orcid.org/0000-0001-7975-2595 \\ Basak Oguz Yolcular ${ }^{3}$ \\ https://orcid.org/0000-0002-6964-1338 \\ Gokhan Koker ${ }^{1}$ \\ https://orcid.org/0000-0003-1745-8002 \\ Abdullah Tokuc ${ }^{1}$ \\ https://orcid.org/0000-0001-8064-1243 \\ Nermin Bayar ${ }^{2}$ \\ https://orcid.org/0000-0001-6785-3137 \\ Sakir Arslan ${ }^{2}$ \\ https://orcid.org/0000-0002-2907-4957
}

\begin{abstract}
Objective: This study was designed to investigate the role of visceral adiposity along with other clinical parameters in predicting poor coronary collateral circulation (CCC) among patients with severe obstructive coronary artery disease (CAD). Subjects and methods: A total of 135 patients with severe obstructive CAD and good ( $n=70)$ or poor $(n=65)$ CCC were included. Data on angiographically detected CCC, the quality criteria for CCC (Rentrop scores) and visceral fat index (VFI) obtained via bioelectrical impedance were compared between good and poor CCC groups. Independent predictors of poor CCC, the correlation between VFI and Rentrop score and the role of VFI in the identification of CCC were analyzed. Results: A significant negative correlation was noted between VFI and Rentrop scores $(r=-0.668,<0.001)$. The presence of hypertension (OR $4.244,95 \% \mathrm{Cl} 1.184$ to $15.211, \mathrm{p}=0.026$ ) and higher VFI (OR $1.955,95 \% \mathrm{Cl} 1.342$ to $2.848, \mathrm{p}<0.001$ ) were shown to be independent predictors of an increased risk for poor CCC. ROC analysis revealed a VFI > 9 (AUC [area under the curve] (95\% $\mathrm{Cl}): 0.898(0.834-0.943), \mathrm{p}<0.0001)$ to be a potential predictor of poor CCC with a sensitivity of $95.38 \%$ and specificity of $85.71 \%$. Conclusion: In conclusion, our findings revealed comorbid hypertension and higher VFI to significantly predict the risk of poor CCC in patients with severe obstructive CAD. Arch Endocrinol Metab. 2020;64(2):150-8
\end{abstract}

\section{Keywords}

Obstructive coronary artery disease; coronary collateral circulation; visceral adiposity; hypertension; body mass index

\section{INTRODUCTION}

$\mathrm{C}$ oronary collateral circulation (CCC) is a physiological adaptation that serves as a natural bypass system to restore blood flow in myocardium jeopardized by stenosis or the occlusion of a coronary vessel $(1,2)$. Well-developed CCC is considered to protect myocardial function by limiting the infarct size and improving survival after transient or permanent coronary obstruction in patients with coronary artery disease (CAD) (2-7). Thus, the identification of factors associated with CCC development is considered to be of great clinical significance $(8,9)$.

Given that coronary collateral growth depends on intact vascular endothelium and endothelial function, factors contributing to vascular dysfunction have also been suggested to be associated with poor CCC (10-12). Accordingly, genetic factors, age, degree of coronary artery stenosis, presence of total occlusion, myocardial ischemia, severe multivessel coronary stenosis, physical exercise, smoking, obesity, hyperlipidemia, diabetes mellitus and metabolic syndrome have been proposed to be related to coronary collateral development in several studies $(10,13-20)$.

However, while many pathogenic insults have been proposed, given the existence of conflicting data, the exact mechanism of CCC has not yet been completely described $(7,11,13,20-22)$. 
Obesity is considered an independent risk factor for cardiovascular disease (CVD), while endothelial dysfunction and subclinical inflammation, along with cardiovascular risk status, have been associated with an increased incidence of $\mathrm{CV}$ events in obese patients (23-25). The increasing demand due to elevated cardiac output combined with the risk of down perfusion via large artery stenosis-dependent flow restriction is considered the main clinical dilemma related to cardiac health in obese patients (26).

Visceral adiposity, rather than general obesity, has been demonstrated in several studies to be more strongly related to complications such as risk of CVD, insulin resistance and type 2 diabetes, while visceral fat was also shown to have greater pro-inflammatory characteristics than subcutaneous fat (27-29). However, no studies to date have investigated the potential role of visceral adiposity in coronary collateral development in patients with severe obstructive CAD. The present study was therefore designed to investigate the role of visceral adiposity along with other clinical parameters in predicting poor CCC among patients with severe obstructive CAD.

\section{SUBJECTS AND METHODS}

\section{Study population}

A total of 135 patients (mean (SD) age: 59.3 (10.3) years, $82.2 \%$ were male) with CAD who had total occlusion of at least one major coronary artery demonstrated by invasive coronary angiography were included in this prospective study conducted between 2017 and 2018. Patients were divided into two groups based on collateral degree: the good CCC group (Rentrop grades $2-3, \mathrm{n}=70$ ) and the poor CCC group (Rentrop grades $0-1, \mathrm{n}=65$ ) according to the Rentrop Cohen classification (30). Patients who were suffering from angina-type chest pain for 3-6 months and who had angiography due to stable angina pectoris that resulted in findings consistent with chronic total occlusion in a coronary artery were included in the study. Patients with a past history of CAD, coronary revascularization, chronic alcohol usage, hepatitis $\mathrm{B}$ and $\mathrm{C}$ infections or chronic kidney disease and patients with diabetes on pioglitazone treatment were excluded from the study.

The study was conducted in full accordance with the local Good Clinical Practice guidelines and current legislations, and permission was obtained from the Clinical Research and Ethics Committee of University of Health Sciences Antalya Training and Research Hospital for the use of patient data for publication purposes (date of approval 19/1/2017; reference number/protocol no: 2/2).

\section{Study parameters}

Data on patient demographics (age, sex), smoking and alcohol consumption, comorbidities (diabetes, hypertension), concomitant medications, CAD characteristics (type and number of occluded coronary arteries), anthropometrics [body mass index (BMI, $\mathrm{kg} / \mathrm{m}^{2}$ ), muscle mass, fat mass, visceral fat index (VFI)], blood biochemistry [total cholesterol, triglycerides, high-density lipoprotein (HDL), lowdensity lipoprotein (LDL), creatinine], hemogram [neutrophil, lymphocyte, thrombocyte, white blood cell (WBC) counts, hemoglobin] and inflammatory markers [C-reactive protein (CRP), neutrophil-tolymphocyte ratio (NLR), platelet-to-lymphocyte ratio (PLR), neutrophil-to-platelet ratio (NPR)] were recorded for each patient and compared between the good and poor CCC groups.

\section{Coronary angiography and collateral grading}

Coronary angiography was performed with the Judkins technique and was evaluated in terms of total coronary occlusion by two experienced cardiologists to determine CCC. Collateral flow was graded using the Rentrop scoring system (0: no visible filling of any collateral channels, 1 : filling of the small side branches, 2: partial collateral filling of the epicardial artery, 3: complete collateral filling of the epicardial artery) (30). Patients were then classified as having poor CCC (Rentrop grades 0 -1) or good CCC (Rentrop grades 2-3).

\section{Blood tests for inflammatory markers}

Serum CRP levels were measured as high-sensitivity $\mathrm{CRP}$ by an immunoturbidimetric assay using the C-Reactive Protein High Sensitivity reagent (Beckman Coulter, Inc., Fullerton, CA, USA; limit of detection, $0.08 \mathrm{mg} / \mathrm{L})$. The NLR, PLR and NPR were calculated as the ratio of the absolute neutrophil or platelet count and the absolute lymphocyte count, provided by the differential white blood cell count (WBC) measured by a Sysmex XE-2100 automated hematology analyzer (Sysmex Corporation). 


\section{Anthropometrics}

Body weight $(\mathrm{kg})$ and height $(\mathrm{m})$ were measured with the participants in a standing position, and BMI $\left(\mathrm{kg} / \mathrm{m}^{2}\right)$ was calculated at the time of body composition measurement. Elementary body composition was measured using a direct segmental multifrequency bioelectrical impedance analyzer (InBody770) to identify total fat mass and total muscle mass. Bioimpedance measurements were performed with attention to the state of hydration (lack of ascites, pleural effusion and pretibial edema), time (on the morning of the first hospitalization day) and clothes worn (with standard clothing and no personal belongings). VFI was assessed to measure visceral fat composition via bioelectrical impendence methods using Omron body fat and weight measurement devices (V-body HBF371; Omron, Kyoto, Japan). To obtain the data of VFI from the resistance between the two hands and feet, an individual's height, weight, age and sex were input into the instrument and the subjects stood on the footplate barefoot and holding the handle electrodes in both hands horizontally forward. The presence of visceral fat was categorized by the threshold values ( $\leq 9$ : normal, 10-14: high, 15-30: very high) provided by the manufacturer with the scale, as graded arbitrarily from 0 to 30 .

\section{Statistical analysis}

Sample size calculation was performed using the $\mathrm{G}^{*}$ Power 3.1.9 program, which revealed that at least 62 patients (31 patients in each group) needed to be included in the study, based on a power of $80 \%$ and a type I error of 0.05 , assuming a correlation coefficient of $\geq 0.3$ between variables. A post hoc power analysis using G Power 3.1 revealed 99.9\% statistical power with a 0.05 alpha level and $\mathrm{d}=1.77$.

Statistical analysis was performed using IBM SPSS Statistics for Windows, Version 22.0 (IBM Corp., Armonk, NY). Fisher's exact test and Pearson chisquare analysis were performed for categorical variables. The normality assumptions of the analysis of the twogroup measurement differences were controlled by the Shapiro-Wilk test. The Mann-Whitney U test was used for the analysis of nonnormally distributed numerical data, while Student's t test was used for normally distributed data. A Spearman correlation test was performed to test relationships of ordinal or quantitative variables with nonnormal distributions.
The ROC curve was plotted to determine the performance of VFI in the identification of CCC by calculating the area under the curve (AUC) values and the ideal cut-off value via ROC analysis. Univariate logistic regression analysis was performed to identify potential risk factors for poor CCC. Variables with a $\mathrm{p}$ value $<0.05$ in the univariate analysis were analyzed further in a multivariate regression model to identify statistically significant risk factors for poor CCC.

Data are expressed as the mean (standard deviation, $\mathrm{SD}$ ) or median (min-max), as appropriate. $\mathrm{p}<0.05$ was considered statistically significant.

\section{RESULTS}

\section{Demographics and clinical characteristics of the patients with good vs. poor CCC}

Overall, CCC was good in $70(51.9 \%)$ patients and poor in $65(48.1 \%)$ patients with occlusion of 1-2 coronary arteries, including the right coronary artery in most of the patients.

Poor vs. good CCC was associated with older patient age (63.3 (9.3) vs. 55.7 (9.9) years, $\mathrm{p}<0.001)$, higher male percentage $(90.8$ vs. $74.3 \%, \mathrm{p}=0.012)$, higher rates of hypertension $(76.9$ vs. $52.9 \%, \mathrm{p}=$ $0.004), \mathrm{ACE} / \mathrm{ARB}(84.6$ vs. $58.6 \%, \mathrm{p}=0.001)$, beta blockers ( 80.0 vs. $62.9 \%, \mathrm{p}=0.028)$ and anticoagulant use (16.9 vs. $1.4 \%, \mathrm{p}=0.002)$ (Table 1 ).

Median (min-max) levels of BMI (28.4 (3.7) vs. $\left.27.0(3.3) \mathrm{kg} / \mathrm{m}^{2}, \mathrm{p}=0.026\right)$, muscle mass ( 56.4 (38.7$67.3)$ vs. $54.4(38-66.6), \mathrm{p}=0.030)$, fat mass $(23.0$ (8.2-41.4) vs. $19.0(8.2-41.4), \mathrm{p}=0.002)$ and VFI $(13.0(7-23)$ vs. $7.0(4-23), \mathrm{p}<0.001)$ were significantly higher in patients with poor vs. good CCC. Compared to those in the good CCC group, a significantly higher percentage of patients in the poor CCC group had VFI $>9$ (95.4 vs. $14.3 \%, \mathrm{p}<0.001)$ (Table 1$)$.

The median (min-max) neutrophil (4600 (2600$7700)$ vs. $\left.5150(2100-8700) / \mathrm{mm}^{3}, \mathrm{p}=0.005\right)$, lymphocyte (2200 (700-3800) vs. 2600 (1300-4600)/ $\left.\mathrm{mm}^{3}, \mathrm{p}=0.001\right)$, thrombocyte $(247000(100000$ $370000)$ vs. $275500(143000-370000) / \mathrm{mm}^{3}, \mathrm{p}=$ $0.010)$ and WBC (7800 (4100-11700) vs. 9300 (5700$\left.12700) / \mathrm{mm}^{3}, \mathrm{p}<0.001\right)$ counts were significantly lower in the poor CCC group than in the good CCC group.

The poor vs. good CCC groups were similar in terms of the lipid profile, TG-HDL-c ratio and inflammatory markers, including CRP, NLR, PLR and NPR (Table 1). 
Table 1. Demographics and clinical characteristics

\begin{tabular}{|c|c|c|c|c|}
\hline & \multirow{2}{*}{ Total $(n=135)$} & \multicolumn{2}{|c|}{ Coronary collateral circulation } & \multirow{2}{*}{$p$ value } \\
\hline & & Poor $(n=65)$ & Good $(n=70)$ & \\
\hline \multicolumn{5}{|l|}{ Demographics } \\
\hline Age (years), mean (SD) & $59.3(10.3)$ & $63.3(9.3)$ & $55.7(9.9)$ & $<0.001$ \\
\hline Sex (Male/Female), n (\%) & $111(82.2) / 24$ (17.8) & $59(90.8) / 6(9.2)$ & $52(74.3) / 18(25.7)$ & $0.012^{3}$ \\
\hline \multicolumn{5}{|l|}{ Comorbidities, n (\%) } \\
\hline Smoking & $36(26.7)$ & $15(23.1)$ & $21(30)$ & $0.363^{3}$ \\
\hline Alcohol & $15(11.1)$ & $5(7.7)$ & $10(14.3)$ & $0.223^{3}$ \\
\hline Diabetes & $57(42.2)$ & $33(50.8)$ & $24(34.3)$ & $0.053^{3}$ \\
\hline Hypertension & 87 (64.4) & $50(76.9)$ & $37(52.9)$ & $0.004^{3}$ \\
\hline \multicolumn{5}{|l|}{ Concomitant medications } \\
\hline CCB, n (\%) & $21(15.6)$ & $9(13.8)$ & $12(17.1)$ & $0.597^{3}$ \\
\hline ACEi/ARB, n (\%) & 96 (71.1) & $55(84.6)$ & $41(58.6)$ & $0.001^{3}$ \\
\hline Beta blocker, n (\%) & 96 (71.1) & $52(80.0)$ & $44(62.9)$ & $0.028^{3}$ \\
\hline Nitrate, n (\%) & $9(6.7)$ & $5(7.7)$ & $4(5.7)$ & $0.738^{3}$ \\
\hline Statin, n (\%) & $129(95.6)$ & 63 (96.9) & $66(94.3)$ & $0.682^{3}$ \\
\hline Antiplatelet, n (\%) & $129(95.6)$ & 60 (92.3) & 69 (98.6) & $0.105^{3}$ \\
\hline Anticoagulant, $\mathrm{n}(\%)$ & $12(8.9)$ & $11(16.9)$ & $1(1.4)$ & $0.002^{3}$ \\
\hline \multicolumn{5}{|l|}{ CAD characteristics } \\
\hline \multicolumn{5}{|l|}{ Occluded coronary artery, n (\%) } \\
\hline Right coronary artery & $96(71.1)$ & $53(81.5)$ & $43(61.4)$ & \\
\hline Obtuse marginal branches 2 & $6(4.4)$ & $4(6.2)$ & $2(2.9)$ & \\
\hline Circumflex & $12(8.9)$ & $2(3.1)$ & $10(14.3)$ & $\mathrm{N} / \mathrm{A}$ \\
\hline Left anterior descending artery & 18 (13.3) & $6(9.2)$ & $12(17.1)$ & \\
\hline Diagonal 1 & $3(2.2)$ & $0(0)$ & $3(4.3)$ & \\
\hline \multicolumn{5}{|l|}{ Number of occluded vessels, $n$ (\%) } \\
\hline 1 & $50(37.0)$ & 27 (41.5) & $23(32.9)$ & \multirow{4}{*}{$0.124^{3}$} \\
\hline 2 & $52(38.5)$ & $26(40.0)$ & $26(37.1)$ & \\
\hline 3 & $24(17.8)$ & $11(16.9)$ & $13(18.6)$ & \\
\hline 4 & $9(6.7)$ & $1(1.5)$ & $8(11.4)$ & \\
\hline \multicolumn{5}{|l|}{ Rentrop score, n (\%) } \\
\hline 0 & $3(2.2)$ & $3(4.6)$ & $0(0)$ & \multirow{4}{*}{ - } \\
\hline 1 & $62(45.9)$ & $62(95.4)$ & $0(0)$ & \\
\hline 2 & $47(34.8)$ & $0(0)$ & $47(67.1)$ & \\
\hline 3 & $23(17)$ & $0(0)$ & $23(32.9)$ & \\
\hline \multicolumn{5}{|l|}{ Anthropometrics } \\
\hline BMl $\left(\mathrm{kg} / \mathrm{m}^{2}\right)$, mean (SD) & $27.6(3.6)$ & $28.4(3.7)$ & $27.0(3.3)$ & $0.026^{1}$ \\
\hline Muscle mass, median (min-max) & $55.9(38-67.3)$ & $56.4(38.7-67.3)$ & $54.4(38-66.6)$ & $0.030^{2}$ \\
\hline Fat mass, median (min-max) & $20.1(8.2-41.4)$ & $23.0(8.2-41.4)$ & $19.0(8.2-41.4)$ & $0.002^{2}$ \\
\hline \multirow[t]{3}{*}{ Median (min-max) } & $12(4-23)$ & $13.0(7-23)$ & $7.0(4-23)$ & $<0.001^{2}$ \\
\hline & $63(46.7)$ & $3(4.6)$ & $60(85.7)$ & \multirow{2}{*}{$<0.001^{3}$} \\
\hline & $72(53.3)$ & $62(95.4)$ & $10(14.3)$ & \\
\hline \multicolumn{5}{|l|}{ Blood biochemistry } \\
\hline Total cholesterol, median (min-max) & $193(87-336)$ & $203(87-336)$ & $191(143-336)$ & $0.798^{2}$ \\
\hline Triglycerides, median (min-max) & $173(51-597)$ & $175(51-597)$ & $151(65-597)$ & $0.292^{2}$ \\
\hline HDL, mean (SD) & $43.2(8.1)$ & $44.1(8.1)$ & $42.3(8.1)$ & $0.198^{1}$ \\
\hline
\end{tabular}




\begin{tabular}{|c|c|c|c|c|}
\hline & \multirow{2}{*}{ Total $(n=135)$} & \multicolumn{2}{|c|}{ Coronary collateral circulation } & \multirow{2}{*}{$\mathrm{p}$ value } \\
\hline & & Poor $(n=65)$ & Good $(n=70)$ & \\
\hline LDL, median (min-max) & $113(37-253)$ & $106(37-253)$ & $121.5(78-253)$ & $0.154^{2}$ \\
\hline Creatinine, mean (SD) & $1.1(0.2)$ & $1.1(0.1)$ & $1(0.2)$ & $<0.001^{1}$ \\
\hline TG/HDL-C, median (min-max) & $3.81(1.38-13)$ & $3.79(1.62-13)$ & $4.14(1.38-11.48)$ & $0.176^{2}$ \\
\hline HbA1c, median (min-max) & $5.7(4-11.5)$ & $6(4.2-11.5)$ & $5.5(4-11.1)$ & $0.203^{2}$ \\
\hline \multicolumn{5}{|l|}{ Hemogram } \\
\hline Neutrophil, median (min-max) & $5000(2100-8700)$ & $4600(2600-7700)$ & $5150(2100-8700)$ & $0.005^{2}$ \\
\hline Lymphocyte, median (min-max) & $2500(700-4600)$ & $2200(700-3800)$ & $2600(1300-4600)$ & $0.001^{2}$ \\
\hline Thrombocyte, median (min-max) & $265000(100000-370000)$ & $247000(100000-370000)$ & $275500(143000-370000)$ & $0.010^{2}$ \\
\hline WBC, median (min-max) & $8500(4100-12700)$ & $7800(4100-11700)$ & $9300(5700-12700)$ & $<0.001^{2}$ \\
\hline Hemoglobin, median (min-max) & $14.2(8.5-17.6)$ & $14.2(8.5-17.6)$ & $14.5(9.9-16.2)$ & $0.425^{2}$ \\
\hline \multicolumn{5}{|c|}{ Inflammatory markers, median (min-max) } \\
\hline CRP & $15(2-101)$ & $12(2-101)$ & $15(2-101)$ & $0.396^{2}$ \\
\hline NLR & $2.1(0.81-5.86)$ & $2.19(1.11-5.86)$ & $1.92(0.81-3.92)$ & $0.155^{2}$ \\
\hline PLR & $0.01(0.003-0.02)$ & $0.01(0.003-0.02)$ & $0.01(0.005-0.02)$ & $0.198^{2}$ \\
\hline NPR & $0.02(0.009-0.031)$ & $0.02(0.01-0.031)$ & $0.02(0.009-0.031)$ & $0.115^{2}$ \\
\hline
\end{tabular}

ACEi/ARB: angiotensin-converting enzyme inhibitor/angiotensin II receptor blockers; BMI: body mass index; CCB: calcium channel blocker; CRP: C-reactive protein; HDL: high-density lipoprotein; LDL: Iow-density lipoprotein; N/A: not applicable; NLR: neutrophil-to-lymphocyte ratio; NPR: neutrophil-to-platelet ratio; PLR: platelet-to-lymphocyte ratio; VFI: visceral fat index; WBC: white blood cell.

${ }^{1}$ Student's t test; ${ }^{2}$ Mann-Whitney U test; ${ }^{3}$ Chi square test.

\section{ROC analysis}

There was a significant negative correlation between VFI and Rentrop scores $(\mathrm{r}=-0.668,<0.001)$. ROC analysis revealed that VFI $>9$ (AUC $(95 \% \mathrm{CI}): 0.898$ (0.834-0.943), $\mathrm{p}<0.0001)$ was a potential marker of poor CCC with a sensitivity of $95.38 \%$ and specificity of $85.71 \%$ (Figure 1).

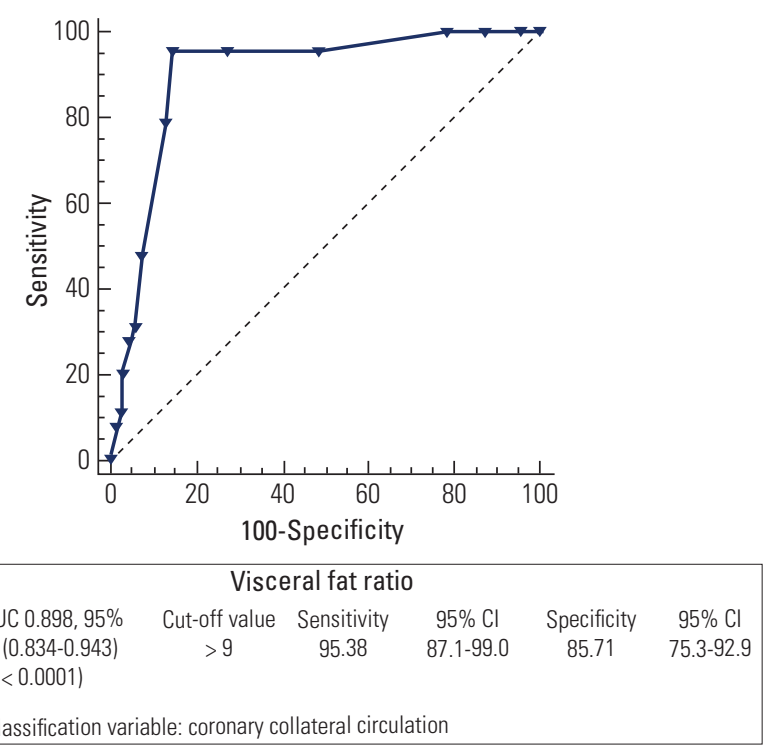

Figure 1. ROC curve analysis of the role of VFI in the prediction of coronary collateral circulation.

AUC: area under the curve.

\section{Logistic regression analysis for independent predictors of poor CCC}

Among the variables significantly associated with poor CCC in the univariate analysis [older age, male sex, hypertension, BMI $>25 \mathrm{~kg} / \mathrm{m}^{2}$, higher muscle mass, fat mass and VFI], only the presence of hypertension (OR 4.244, 95\% CI 1.184 to $15.211, \mathrm{p}=0.026)$ and higher VFI (OR 1.955, 95\% CI 1.342 to 2.848 , p < 0.001 ) were shown to be independent predictors of an increased risk for poor CCC (Table 2).

\section{DISCUSSION}

Our findings in a cohort of CAD patients with total coronary occlusion revealed the presence of hypertension and higher VFI to be significant determinants of poor CCC development. To the best of our knowledge, the present study is the first clinical study to identify an increase in visceral fat as a potential independent predictor of poor collateral development.

The presence of metabolic syndrome (31-33), an increasing number of components of metabolic syndrome $(33,34)$, aging (15), obesity (18) and the presence of hypertension $(20,35)$ have been associated with an increased risk of impaired collateral development among patients with obstructive CAD. 
However, there is controversy regarding the impact of diabetes or smoking on collateral development, with associations of diabetes $(10,11)$ and nonsmoking (20) with a higher risk of poor collateral development shown in some studies, whereas no associations of diabetes (36) or smoking (13) with collateral growth and an association of inflammation with either promoted or inhibited collateral growth (37) have been reported in other studies.

In addition, a positive association of leukocytes (38) and inflammatory cytokines (39) with collateral development has also been documented in healthy animal models. Higher neutrophil and monocyte count (22) and mean platelet volume (40) and lower lymphocyte count (22) upon admission were reported to be associated with better collateral networks in patients with acute coronary syndrome, while elevated hs-CRP levels $(11,41,42)$ have been associated with an increased risk of impaired collateral development among patients with obstructive CAD.

Our findings revealed no association of inflammatory markers (CRP, NLR, PLR), lipid profile (LDL, HDL, triglycerides, total cholesterol, TG-HDL-c ratio), diabetes or smoking with coronary collateral development. Although older age, male sex, BMI $>25 \mathrm{~kg} / \mathrm{m}^{2}$ and higher muscle and fat mass were also among the factors significantly associated with poor CCC in the univariate analysis, multivariate analysis revealed hypertension and higher VFI to be the only independent predictors of poor CCC.

Visceral adipose tissue is a metabolically active organ, and excess levels of visceral adipose tissue, regardless of BMI, is considered an independent risk factor for diabetogenic and atherogenic abnormalities (43-45). Visceral fat was also shown to be a stronger risk factor for CVD than BMI or other fat depots (27). Thus, the assessment of both general and abdominal adiposity has been suggested to provide a better assessment of mortality risk, particularly among people with a lower BMI (46).

VFI is considered to be an accurate and reliable method for evaluating visceral adiposity and has been shown to be highly relevant to visceral fat measured by the gold standard methods (47-50). In our study, measurements were based on bioimpedance analysis, which is a low cost, easily applied technique associated with a globally accepted standardization and a low risk of bias if measurements are performed appropriately. To the best of our knowledge, the present study is the first clinical study to show an increase in visceral fat as a potential independent predictor of poor collateral development. In addition to its significant negative correlation with Rentrop scores, VFI (cut off value > 9) was also shown to predict the likelihood of poor CCC with a sensitivity of $95.38 \%$ and a specificity of $85.71 \%$. Likewise, in a past study comparing the levels of pericardial fat index, paracardial fat index, and visceral fat index in patients with vs. without CAD, the levels of these fat indices were shown to be significantly higher in the CAD group and positively correlated with the number of significantly stenosed coronary vessels and the Gensini score in CAD patients (51).

Thus, in light of clinical entities, such as "metabolically healthy" obesity phenotypes and the "obesity paradox" (52), our findings emphasize the consideration of visceral adiposity rather than BMI as a more adequate indicator of collateral development, which plays a major role in cardiovascular outcomes and survival $(3,5,7,13)$. Similarly, in a communitybased cross-sectional study regarding obesity indices

Table 2. Univariate and multivariate logistic regression analyses for independent predictors of poor CCC

\begin{tabular}{|c|c|c|c|c|}
\hline \multirow{2}{*}{ Variables } & \multicolumn{2}{|c|}{ Univariate analysis } & \multicolumn{2}{|c|}{ Multivariate analysis } \\
\hline & OR (95\% Cl) & $p$ value & OR (95\% Cl) & p value \\
\hline Age & $1.084(1.042-1.128)$ & $<0.001$ & $0.988(0.896-1.09)$ & 0.816 \\
\hline $\operatorname{Sex}(M / F)$ & $3.404(1.257-9.219)$ & 0.016 & $0.051(0.001-2.996)$ & 0.152 \\
\hline $\mathrm{BMl}>25$ & 2.691 (1.164-6.224) & 0.021 & $0.988(0.146-6.696)$ & 0.990 \\
\hline DM & $1.977(0.989-3.952)$ & 0.054 & $2.262(0.666-7.68)$ & 0.191 \\
\hline Hypertension & $2.973(1.413-6.255)$ & 0.004 & $4.088(1.154-14.482)$ & 0.029 \\
\hline Muscle mass & $1.057(1.011-1.105)$ & 0.014 & $1.084(0.928-1.265)$ & 0.310 \\
\hline Fat mass & $1.084(1.028-1.142)$ & 0.003 & $0.82(0.667-1.009)$ & 0.061 \\
\hline VFI & 1.691 (1.437-1.990) & $<0.001$ & $2.054(1.403-3.005)$ & $<0.001$ \\
\hline
\end{tabular}

BMI: body mass index; Cl: confidence interval; DM: diabetes mellitus; OR: odds ratio; VFI: visceral fat index. 
and myocardial infarction, VFI (optimal cut-off values of 15 for males and 10 for females) was shown to be associated with higher predictive power and higher sensitivity than BMI and waist circumference in the identification of CVD risk in both sexes (53).

In addition, the significant role of VFI in the prediction of poor CCC seems to indicate the likelihood of considering visceral adiposity as a potential target, with maintenance of VFI values below 9 suggested for the prevention of poor collateral growth in patients with $\mathrm{CV}$ risk factors in the long term.

Hypertension was shown to be a strong independent risk factor for poor CCC in our cohort of patients with total coronary occlusion. This finding seems to be in line with the association of hypertension with an increased risk of impaired collateral development in patients with coronary occlusion reported in past studies $(20,35)$. Notably, in a past study among patients with single chronic total occlusion of the coronary artery, a J-shaped relationship was noted between diastolic blood pressure (DBP) and CCC (54). The authors indicated a decrease in the incidence of poor CCC as DBP increased, while poor CCC increased as DBP increased further to $>95 \mathrm{mmHg}$ (54). Given that most coronary blood flow to the myocardium occurs in diastole, the authors suggested that DBP may influence the tangential fluid shear stress of the endothelial surface by modulating the coronary artery blood flow velocity in diastole, thereby affecting the development of CCC (54). The authors also emphasized that excessively high DBP might lead to stenosis in the CCC-fed coronary artery, which in turn would decrease the perfusion of CCC (54).

\section{Study limitations}

The main limitation of this study seems to be the assessment of visceral fat based on VFI, without the inclusion of gold-standard adiposity measurements such as micromagnetic resonance imaging ( $\mu M R I)$ and microcomputed tomography $(\mu \mathrm{CT})$, which otherwise would extend the knowledge achieved in the current study. However, $\mu \mathrm{CT}$ is an expensive method with considerable radiation risk that limits its use in every patient and only for the purpose of visceral fat measurement, while $\mu \mathrm{MRI}$ is a very expensive and time-consuming method that is not appropriate for use in visceral fat measurement. Accordingly, given the limitations of the other two techniques, the use of bioimpedance analysis seems to be a clinically feasible approach for visceral fat measurement based on the extensive literature support. Nonetheless, given the restricted amount of data available on the potential role of visceral adiposity in collateral development in patients with coronary occlusion, our findings represent a valuable contribution to the literature.

In conclusion, our findings revealed that comorbid hypertension and higher VFI (cut off value >9) significantly predict the risk of poor CCC with a sensitivity of $95.38 \%$ and specificity of $85.71 \%$. Thus, there may be a potential clinical role of visceral adiposity assessment in the diagnosis of poor collateral development, and we may consider visceral adiposity as a potential target for preventing poor collateral circulation in patients with established CV risk in the long term.

Funding: this research received no specific grant from any funding agency in the public, commercial, or not-for-profit sectors.

Disclosure: no potential conflict of interest relevant to this article was reported.

\section{REFERENCES}

1. Seiler C. The human coronary collateral circulation, Eur J Clin Invest. 2010;40:465-76.

2. Seiler C, Stoller M, Pitt B, Meier P.The human coronary collateral circulation: development and clinical importance. Eur Heart J. 2013;34:2674-82.

3. Habib GB, Heibig J, Forman SA, Brown BG, Roberts R, Terrin ML, et al. Influence of coronary collateral vessels on myocardial infarct size in humans. Results of phase I thrombolysis in myocardial infarction (TIMI) trial. The TIMI Investigators. Circulation. 1991;83:739-46.

4. Smith RD, Ilsley CD. Clinical contribution of the collateral circulation to myocardial protection. Coron Artery Dis. 2004;15:393-8.

5. Hansen JF. Coronary collateral circulation, clinical significance and influence on survival in patients with coronary artery disease. Am Heart J. 1989;117:290-5.

6. Meier P, Hemingway H, Lansky AJ, Knapp G, Pitt B, Seiler C. The impact of the coronary collateral circulation on mortality: a metaanalysis. Eur Heart J. 2012;33:614-21.

7. Billinger M, Kloos P, Eberli FR, Windecker S, Meier B, Seiler C. Physiologically assessed coronary collateral flow and adverse cardiac ischemic events: a follow up study in 403 patients with coronary artery disease. J Am Coll Cardiol. 2002;40:1545e50.

8. Fei Y, Hou J, Xuan W, Zhang C, Meng X. The relationship of plasma miR-503 and coronary collateral circulation in patients with coronary artery disease. Life Sci. 2018;207:145-51.

9. Yan Y, Song D, Liu L, Meng X, Qi C, Wang J. The relationship of plasma decoy receptor 3 and coronary collateral circulation in patients with coronary artery disease. Life Sci. 2017;189:84-8.

10. Abaci A, Oğuzhan A, Kahraman S, Eryol NK, Unal S, Arinç H, et al. Effect of diabetes mellitus on formation of coronary collateral vessels. Circulation. 1999;99:2239-42.

11. Sögüt $E$, Kadi H, Karayakalı M, Mertoğlu C. The association of plasma vitamin $A$ and $E$ levels with coronary collateral circulation. Atherosclerosis. 2015;239:547-51. 
12. Fan Y, Hu JS, Guo F, Lu ZB, Xia H. Lipoprotein(a) as a predictor of poor collateral circulation in patients with chronic stable coronary heart disease. Braz J Med Biol Res. 2017;50:e5979.

13. Akboga MK, Akyel A, Sahinarslan A, Demirtas CY, Yayla C, Boyaci $B$, et al. Relationship between plasma apelin level and coronary collateral circulation. Atherosclerosis. 2014;235:289-94.

14. PohIT, Seiler C, Billinger M, Herren E, Wustmann K, Mehta H, et al. Frequency distribution of collateral flow and factors influencing collateral channel development. Functional collateral channel measurement in 450 patients with coronary artery disease. J Am Coll Cardiol. 2001;38:1872-8.

15. Kurotobi T, Sato H, Kinjo K, Nakatani D, Mizuno H, Shimizu M, et al.; OACIS Group. Reduced collateral circulation to the infarctrelated artery in elderly patients with acute myocardial infarction. J Am Coll Cardiol. 2004;44:28-34.

16. Sun Z, Shen Y, Lu L, Zhang RY, Pu LJ, Zhang Q, et al. Clinical and angiographic features associated with coronary collateralization in stable angina patients with chronic total occlusion. J Zhejiang Univ Sci B. 2013;14:705-12.

17. Kornowski R. Collateral formation and clinical variables in obstructive coronary artery disease: the influence of hypercholesterolemia and diabetes mellitus. Coron Artery Dis. 2003;14:61-4.

18. Yilmaz MB, Biyikoglu SF, Akin Y, Guray U, Kisacik HL, Korkmaz $\mathrm{S}$. Obesity is associated with impaired coronary collateral vessel development. Int J Obes Relat Metab Disord. 2003;27:1541-5.

19. van der Hoeven NW, Teunissen PF, Werner GS, Delewi R, Schirmer $\mathrm{SH}$, Traupe T, et al. Clinical parameters associated with collateral development in patients with chronic total coronary occlusion. Heart. 2013;99:1100-5.

20. Koerselman J, de Jaegere PP, Verhaar MC, Grobbee DE, van der GraafY. SMART Study Group. Coronary collateral circulation: the effects of smoking and alcohol. Atherosclerosis. 2007;191:191-8.

21. Koerselman J, van der Graaf $Y$, de Jaegere PP, Grobbee DE. Coronary collaterals: an important and underexposed aspect of coronary artery disease. Circulation. 2003;107:2507-11.

22. Tenekecioglu E, Yılmaz M, Karaagac K, Bekler A, Aslan B, Demir $S$, et al. Predictors of coronary collaterals in patients with non ST-elevated acute coronary syndrome: the paradox of the leukocytes. Cent Eur J Immunol. 2014;39:83-90.

23. Poirier P, Giles TD, Bray GA, HongY, Stern JS, Pi-Sunyer FX, et al. Obesity and cardiovascular disease: pathophysiology, evaluation, and effect of weight loss: an update of the 1997 American Heart Association Scientific Statement on Obesity and Heart Disease from the Obesity Committee of the Council on Nutrition, Physical Activity, and Metabolism. Circulation. 2006;113:898-918.

24. Poirier P, Eckel RH. Obesity and cardiovascular disease. Curr Atheroscler Rep. 2002;4:448-53.

25. Garcia-Labbé D, Ruka E, Bertrand OF, Voisine P, Costerousse O, Poirier P. Obesity and coronary artery disease: evaluation and treatment. Can J Cardiol. 2015;31:184-94.

26. Belin de Chantemele EJ, Stepp DW. Influence of obesity and metabolic dysfunction on the endothelial control in the coronary circulation. J Mol Cell Cardiol. 2012;52:840-7.

27. Finelli C, Sommella L, Gioia S, La Sala N, Tarantino G. Should visceral fat be reduced to increase longevity? Ageing Res Rev. 2013;12:996-1004.

28. Carr DB, Utzschneider KM, Hull RL, Kodama K, Retzlaff BM, Brunzell JD, et al. Intra-abdominal fat is a major determinant of the National Cholesterol Education Program AdultTreatment Panel III criteria for the metabolic syndrome. Diabetes. 2004;53:2087-94.

29. Zamboni M, Armellini F, Sheiban I, De Marchi M, Todesco T, Bergamo-Andreis IA, et al. Relation of body fat distribution in men and degree of coronary narrowings in coronary artery disease. Am J Cardiol. 1992:70:1135-8.
30. Rentrop KP, Cohen M, Blanke H, Phillips RA. Changes in collateral channel filling immediately after controlled coronary artery occlusion by an angioplasty balloon in human subjects. J Am Coll Cardiol. 1985;5:587-92.

31. Turhan H, Yasar AS, Erbay AR, Yetkin E, Sasmaz H, Sabah I. Impaired coronary collateral vessel development in patients with metabolic syndrome. Coron Artery Dis. 2005;16:281-5.

32. Yilmaz MB, Caldir V, Guray Y, Guray U, Altay H, Demirkan B, et al. Relation of coronary collateral vessel development in patients with a totally occluded right coronary artery to the metabolic syndrome. Am J Cardiol. 2006;97:636-9.

33. Mouquet $F$, Cuilleret $F$, Susen $S$, Sautière $K$, Marboeuf $P$, Ennezat $\mathrm{PV}$, et al. Metabolic syndrome and collateral vessel formation in patients with documented occluded coronary arteries: association with hyperglycemia, insulin-resistance, adiponectin and plasminogen activator inhibitor-1. Eur Heart J. 2009;30:840-9.

34. Sasmaz H, Yilmaz MB. Coronary collaterals in obese patients: impact of metabolic syndrome. Angiology. 2009;60:164-8.

35. Koerselman J, de Jaegere PP, Verhaar MC, van der Graaf $Y$, Grobbee DE. High blood pressure is inversely related with the presence and extent of coronary collaterals. J Hum Hypertens. 2005; 19:809-17.

36. Zbinden R, Zbinden S, Billinger M, Windecker S, Meier B, Seiler C. Influence of diabetes mellitus on coronary collateral flow: an answer to an old controversy. Heart. 2005;91:1289-93.

37. Teunissen PF, Horrevoets AJ, van Royen N. The coronary collateral circulation: genetic and environmental determinants in experimental models and humans. $\mathrm{J}$ Mol Cell Cardiol. 2012;52:897-904.

38. Meisner JK, Price RJ. Spatial and temporal coordination of bone marrowderived cell activity during arteriogenesis: regulation of the endogenous response and therapeutic implications. Microcirculation. 2010;17:583-99.

39. Rocic P. Why is coronary collateral growth impaired in type II diabetes and the metabolic syndrome? Vascul Pharmacol. 2012;57:179-86

40. Duran M, Gunebakmaz O, Uysal OK, Ocak A, Yilmaz Y, Arinc H, et al. Relation between mean platelet volume and coronary collateral vessels in patients with acute coronary syndromes. $J$ Cardiol. 2013;61:295-8.

41. Zorkun C, Akkaya E, Zorlu A, Tandogan I. Determinants of coronary collateral circulation in patients with coronary artery disease. Anadolu Kardiyol Derg. 2013;13:146-51.

42. Gulec S, Ozdemir AO, Maradit-Kremers H, Dincer I, Atmaca $Y$ Erol C. Elevated levels of $\mathrm{C}$-reactive protein are associated with impaired coronary collateral development. Eur J Clin Invest. 2006:36:369-75.

43. Schuster J, Vogel P, Eckhardt C, Morelo SD. Applicability of the visceral adiposity index (VAl) in predicting components of metabolic syndrome in young adults. Nutr Hosp. 2014;30:806-12.

44. Despres JP. Body fat distribution and risk of cardiovascular disease: an update. Circulation. 2012;126:1301-13.

45. Despres JP, Moorjani S, Lupien PJ, Tremblay A, Nadeau A, Bouchard C. Regional distribution of body fat, plasma lipoproteins, and cardiovascular disease. Arteriosclerosis. 1990;10:497-511.

46. Pischon $T$, Boeing $H$, Hoffmann $K$, Bergmann $M$, Schulze $M B$, Overvad K, et al. General and abdominal adiposity and risk of death in Europe. N Engl J Med. 2008;359:2105-20.

47. Tian Z, Li Y, Mao Z, Yu S, Wang Y, Liu X, et al. Sex-specific relationship between visceral fat index and dyslipidemia in Chinese rural adults: The Henan Rural Cohort Study. Prev Med. 2018;116:104-11.

48. Amato MC, Pizzolanti G, Torregrossa V, Misiano G, Milano S, Giordano C. Visceral adiposity index (VAl) is predictive of an 
altered adipokine profile in patients with type 2 diabetes. PLoS One. 2014;9:e91969.

49. Amato MC, Giordano C, Galia M, Criscimanna A, Vitabile S, Midiri $M$, et al. Visceral Adiposity Index: a reliable indicator of visceral fat function associated with cardiometabolic risk. Diabetes Care. 2010;33:920-2.

50. DuT, Zhang J, Yuan G, Zhang M, Zhou X, Liu Z, et al. Nontraditional risk factors for cardiovascular disease and visceral adiposity index among different body size phenotypes. Nutr Metab Cardiovasc Dis. 2015;25:100-7.

51. UedaY, ShigaY, Idemoto Y,Tashiro K, Motozato K, Koyoshi R, et al. Association between the presence or severity of coronary artery disease and pericardial fat, paracardial fat, epicardial fat, visceral fat, and subcutaneous fat as assessed by multi-detector row computed tomography. Int Heart J. 2018;59:695-704.

52. Ansaldo AM, Montecucco F, Sahebkar A, Dallegri F, Carbone F. Epicardial adipose tissue and cardiovascular diseases. Int $\mathrm{J}$ Cardiol. 2018 Oct 1. pii: S0167-5273(18)33687-8.

53. Chen Y, Jiang J, Shi J, et al. Association of Visceral Fat Index and Percentage Body Fat and Anthropometric Measures with Myocardial Infarction and Stroke. J Hypertens. 2016;5:235.

54. Shu W, Da WJ, Fu LC, Jing J, Jun G, Hong FZ, et al. The J-curve relationship between diastolic pressure and coronary collateral circulation in patients with single chronic total occlusion. Atherosclerosis. 2014;232:220-3. 